\title{
Analysis of factors associated with local recurrence after endoscopic resection of gastric epithelial dysplasia: a retrospective study
}

Min Kyung Back ${ }^{1}$, Hee Seok Moon ${ }^{1,2^{*}}$, In Sun Kwon ${ }^{3}$, Jae Ho Park', Ju Seok Kim', Sun Hyung Kang ${ }^{1}$, Jae Kyu Sung ${ }^{1}$, Eaum Seok Lee', Seok Hyun Kim', Byung Seok Lee ${ }^{1}$ and Hyun Yong Jeong ${ }^{1}$

\begin{abstract}
Background: Endoscopic mucosal resection (EMR) and endoscopic submucosal dissection (ESD) are widely used techniques for the treatment of gastric epithelial dysplasia. Previous studies have compared the clinical outcome of endoscopic resection for early gastric cancer, but few studies have focused on gastric dysplasia alone. This study aimed to evaluate the long-term prognosis following endoscopic procedures for gastric epithelial dysplasia, investigate differences in local recurrence rates according to the treatment modality, and identify risk factors associated with local recurrence.

Methods: In this retrospective study, local recurrence rates and risk factors associated with local recurrence were compared between 599 patients who underwent EMR and 306 who underwent ESD for gastric epithelial dysplasia from January 2011 to December 2015.

Results: The en bloc resection rate $(32.2 \%$ vs. $100 \%, p<0.001)$ and complete resection rate $(94.8 \%$ vs. $99.0 \%, p=0.003)$ were significantly lower in the EMR group than in the ESD group. The local recurrence rate was significantly lower in the ESD group (1.3\%) than in the EMR group (4.2\%; $p=0.026)$. There was a significantly increased risk of local recurrence, regardless of lesion location or histologic grade, in patients with lesions $>2 \mathrm{~cm}(p=0.002)$ or red in color $(p=0.03)$. The ESD group had a significantly lower local recurrence rate, with a higher complete resection rate, than that in the EMR group $(p<0.05)$. In the case of recurrence after endoscopic resection, most of the recurred lesions were removed through additional endoscopic procedures; there was no difference between the two groups $(p=0.153)$.

\footnotetext{
* Correspondence: mhs1357@cnuh.co.kr

'Division of Gastroenterology, Department of Internal Medicine, Chungnam

National University Hospital, Chungnam National University School of

Medicine, 282 Munhwa-ro, Jung-gu, Daejeon 35015, Korea

2Division of Gastroenterology, Department of Internal Medicine, Chungnam

National University Hospital, Chungnam National University School of

Medicine, 282 Munhwa-ro, Jung-gu, Daejeon 35015, Republic of Korea

Full list of author information is available at the end of the article
}

(c) The Author(s). 2020 Open Access This article is licensed under a Creative Commons Attribution 4.0 International License, which permits use, sharing, adaptation, distribution and reproduction in any medium or format, as long as you give appropriate credit to the original author(s) and the source, provide a link to the Creative Commons licence, and indicate if changes were made. The images or other third party material in this article are included in the article's Creative Commons licence, unless indicated otherwise in a credit line to the material. If material is not included in the article's Creative Commons licence and your intended use is not permitted by statutory regulation or exceeds the permitted use, you will need to obtain permission directly from the copyright holder. To view a copy of this licence, visit http://creativecommons.org/licenses/by/4.0/ The Creative Commons Public Domain Dedication waiver (http://creativecommons.org/publicdomain/zero/1.0/) applies to the data made available in this article, unless otherwise stated in a credit line to the data. 
(Continued from previous page)

Conclusions: The complete resection rate was significantly higher, and the local recurrence rate was significantly lower, in patients with gastric epithelial dysplasia treated with ESD. Therefore, ESD should be considered the preferred treatment in patients with lesions $>2 \mathrm{~cm}$ or showing redness due to an increased risk of local recurrence and EMR may be possible for low-grade dysplasia that is less than $2 \mathrm{~cm}$ without surface changes such as redness, depression and nodularity.

Keywords: Gastric dysplasia, Endoscopic treatment, Local recurrence, Endoscopic resection

\section{Background}

Gastric adenoma or dysplasia can be defined as a precancerous lesion or an atypical change originating from the stomach epithelium. Approximately $11 \%$ of gastric dysplasias are reported to progress to cancer within 4 years. Moreover, 8-59\% of gastric dysplasias are associated with gastric cancer [1].

Endoscopic mucosal resection (EMR) and endoscopic submucosal dissection (ESD) are widely used techniques for the treatment of gastric epithelial dysplasia. Because high-grade dysplasia (HGD) is an obvious precancerous lesion, aggressive treatment such as surgical resection or endoscopic treatment is required. However, low-grade dysplasia (LGD) is associated with a relatively low (3-9\%) incidence of gastric cancer [2]. Histological examination of resected lesions following endoscopic treatment for dysplasia may lead to an upgrade of the final diagnosis. Therefore, there is a continuing debate as to whether an aggressive LGD treatment or selective treatment of lesions with risk factors for cancer is needed. Therefore, this study aimed to evaluate the long-term prognosis following endoscopic procedures for gastric epithelial dysplasia, to investigate differences in local recurrence rates according to treatment modality, and to evaluate risk factors associated with the local recurrence of dysplasia.

\section{Methods \\ Patients}

A total of 2517 patients treated with endoscopic resection at Chungnam National University Hospital (CNUH) from January 2011 to December 2015 were screened (Fig. 1). Among these, 857 patients were excluded from the study because they were not diagnosed with gastric dysplasia at the initial endoscopic biopsy (e.g., adenocarcinoma, neuroendocrine tumor, hyperplastic polyp, lipoma, intestinal metaplasia). In addition, 755 patients were excluded because they were not followed up for more than 1 year after endoscopic resection. As a result, a total of 905 patients diagnosed with LGD or HGD by initial endoscopic biopsy were included in the study. All patients underwent endoscopic resection through EMR or ESD, regardless of the lesion size. EMR and ESD were performed in 66.2\% $(n=599)$ and $33.8 \%(n=306)$ of cases, respectively. Data regarding comorbidities (i.e.,

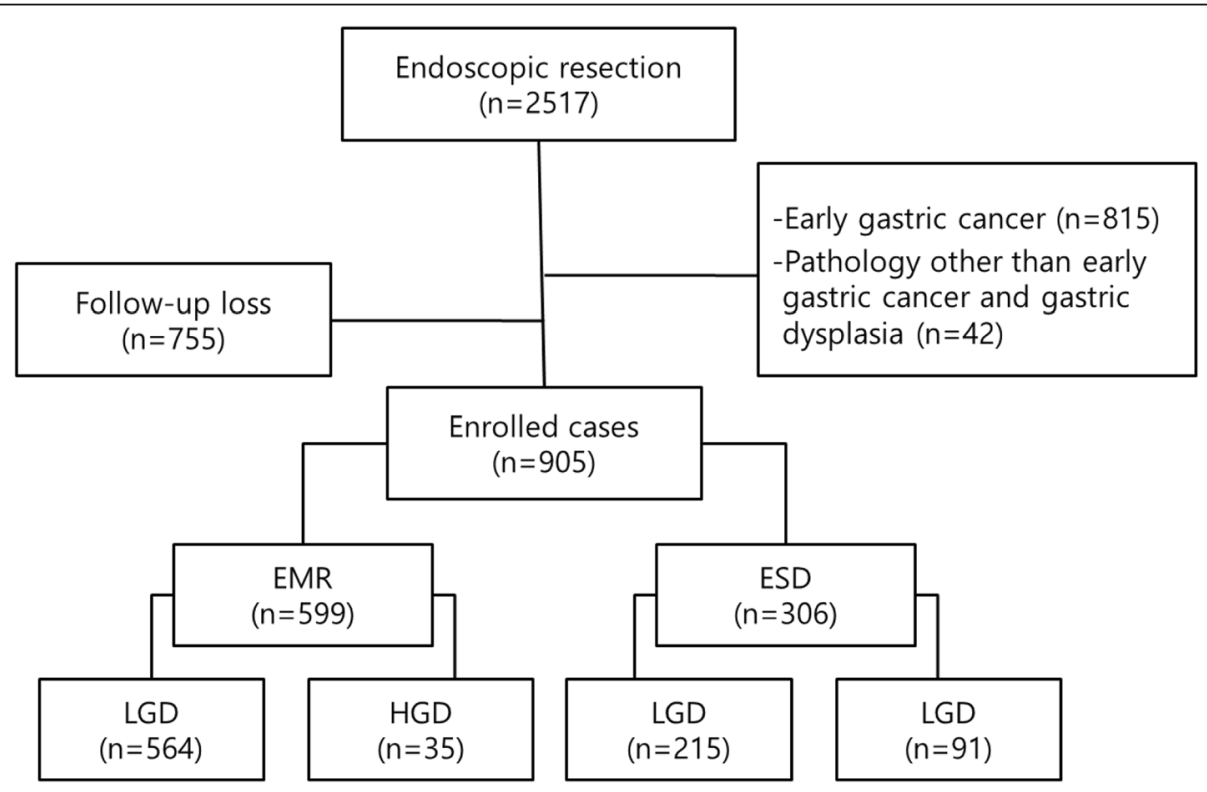

Fig. 1 Flowchart of patient enrollment. The clinical outcomes after endoscopic resection of gastric dysplasia in 905 patients were analyzed. EMR, endoscopic mucosal resection; ESD, endoscopic submucosal dissection; HGD, high-grade dysplasia; LGD, low-grade dysplasia 
hypertension, diabetes mellitus, chronic obstructive pulmonary disease, or chronic kidney disease), smoking history, and alcohol consumption history were collected by medical record review.

\section{Evaluation of endoscopic features}

The surface gross type (i.e., elevated, flat, depressed, or nodularity), color change (i.e., whitish or redness), size, location, atrophic gastritis, and intestinal metaplasia were determined by a review of endoscopic recordings and photographs. Lesion location was classified by dividing the stomach in three equal sections: upper (fundus and upper body), middle (middle and lower body), and lower (angle and antrum). Lesion size was classified as $2.0 \mathrm{~cm}$ or $>2.0 \mathrm{~cm}$.

\section{EMR/ESD techniques}

The approach to endoscopic resection for gastric dysplasia was determined by the endoscopists, in consideration of the lesion characteristics, such as size, shape, and location.

During the procedure, midazolam or diazepam was administered intravenously for sedation, and cardiorespiratory functions were monitored. A dual-channel gastroduodenoscope (GIF-ITQ $260 \mathrm{M}$; Olympus, Japan) was used for EMR and a single-channel gastroduodenoscope (GIF-H260; Olympus) was used for ESD.

Before endoscopic resection, $0.1 \%$ indigo carmine solution was applied to the lesion to identify its location and margins. After confirming the lesion, areas of the normal mucosa $1-2 \mathrm{~mm}$ away from the margin of the lesion were marked with a fixed flexible snare (KachuTechnology Co., Ltd. Korea) or electrosurgical generator (ERBE VIO300D VIO 300D; Erbe, Tübingen, Germany). Then, a saline solution containing diluted epinephrine (1:10, 000) was injected into the submucosal layer of the lesion using needle forceps, and the mucosal layer was completely floated from the muscular layer of the lesion. These procedures were the same for both EMR and ESD, but the subsequent steps differed. For EMR, the lesion was pulled using grasping forceps, and en bloc resection was performed by using a snare loop to cover all marked regions at once; if en bloc resection was impossible, a piecemeal resection was performed (Fig. 2). For ESD, an incision was made with a fixed flexed snare outside the marker, and a circumferential incision was performed using an IT knife (single-use electrosurgical knife KD-61 1 L; Olympus). Then, the submucosal layer was dissected until the lesion was completely resected using an IT knife.

During or after endoscopic resection, endoscopic hemostasis was performed for any bleeding or exposed vessels using an IT knife or hemostatic forceps (FD410LR; Olympus) (Fig. 3). Figure 2 shows the process of en bloc resection of a gastric dysplasia by EMR, and Fig. 3 shows the process of en bloc resection of a gastric dysplasia (approximately $2 \mathrm{~cm}$ in size) by ESD.

\section{Definitions}

En bloc resection was defined as resection of a lesion in one piece (as opposed to piecemeal resection) [3]. Complete resection was defined as $\mathrm{R} 0$ resection in which the resected lesion was pathologically free of dysplasia in the lateral and deep margins. After the procedure, patients were evaluated for complications such as bleeding, perforation, and pyloric stenosis. Delayed bleeding was defined as hematemesis or melena, with a decrease in the hemoglobin level of more than $2 \mathrm{~g} / \mathrm{dl}$, requiring endoscopic hemostasis after endoscopic resection [3, 4]. Perforation was defined as direct perforation of the mesenteric fat during endoscopic procedures or free air on

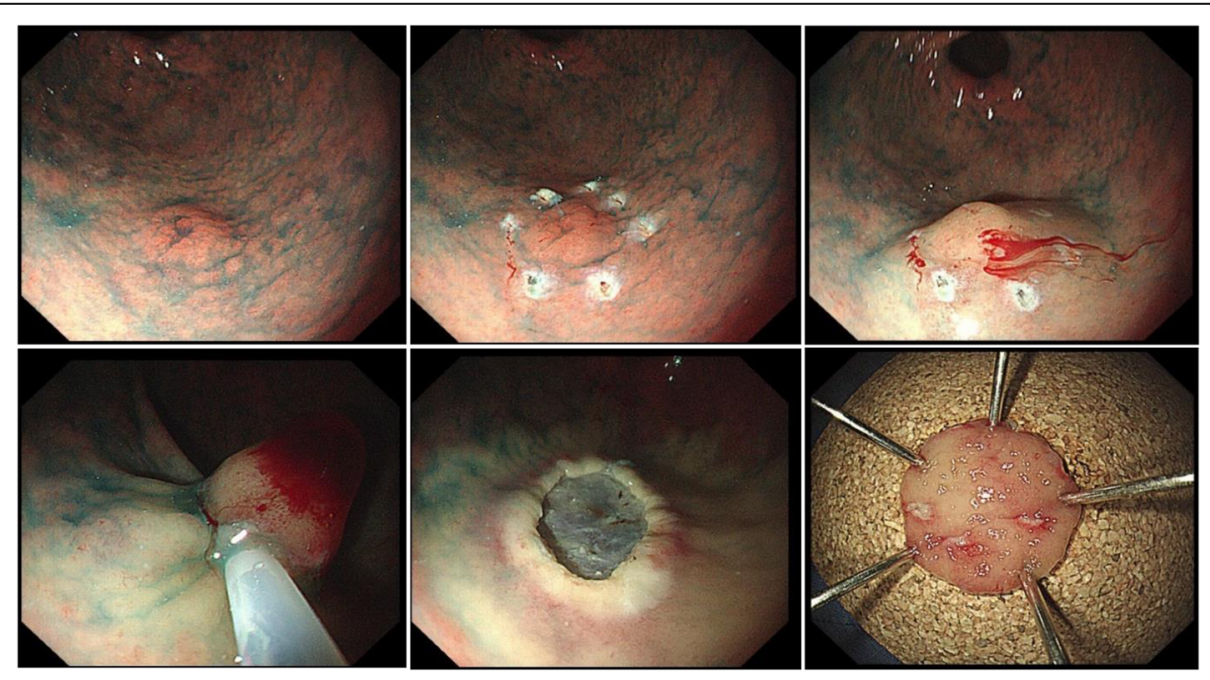

Fig. 2 Endoscopic mucosal resection procedure 


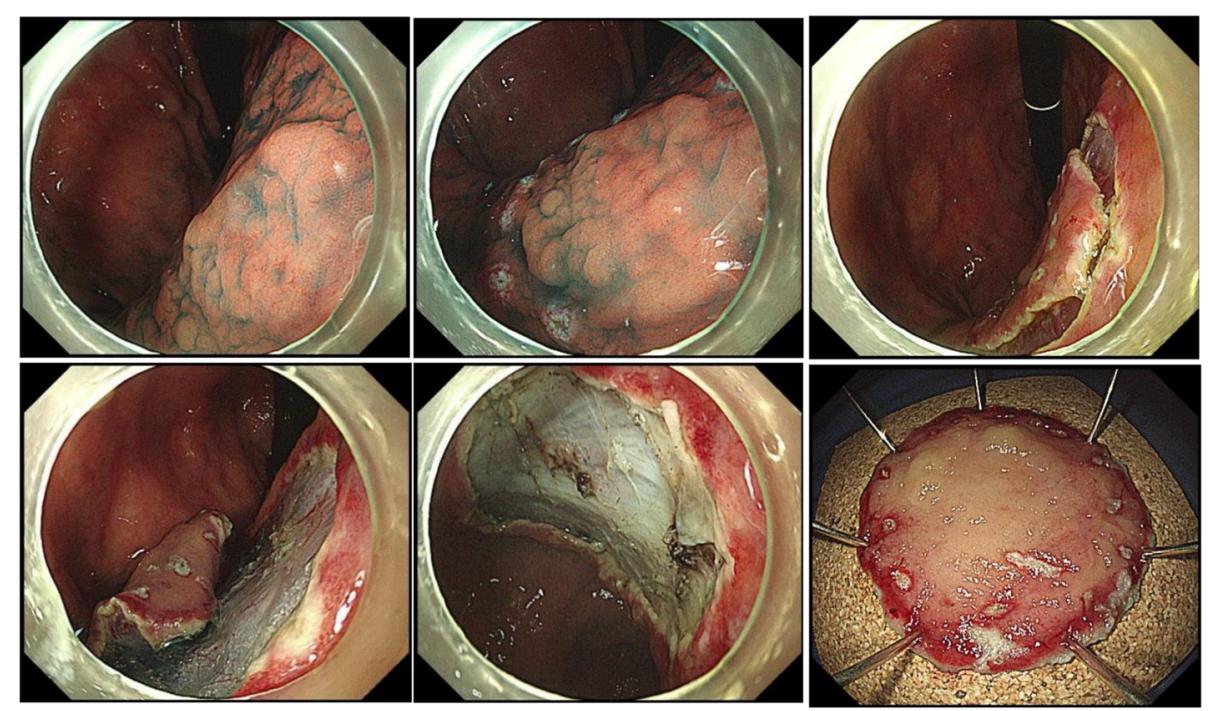

Fig. 3 Endoscopic submucosal dissection procedure

abdominal x-ray examination after endoscopic resection [3]. Pyloric stenosis was defined as the occurrence of symptoms such as dyspepsia due to a narrowing of the pyloric ring precluding passage of an endoscopic fiber after endoscopic resection [5].

\section{Histological analysis}

All specimens collected for histological analysis were immediately fixed into paraffin blocks using a neutral buffer with $10 \%$ formalin. Paraffin blocks were cut at $2-\mathrm{mm}$ intervals and stained with hematoxylin and eosin to confirm complete resection [2]. The presence of Helicobacter pylori was evaluated by the rapid urease test (CLO1 test; Kimberly-Clark, UT) and histologic examination (WrightGiemsa stain). If any test results were positive, $H$. pylori infection was considered as present. Histologic diagnosis was made by experienced pathologists, in accordance with the Vienna classification of gastric epithelial dysplasia [6].

\section{Follow-up and confirmation of local recurrence}

All patients had their first follow-up endoscopy at 3 or 6 months after endoscopic resection, and annually thereafter. During the follow-up endoscopy, a biopsy was performed when an abnormality was found, such as an overgrowth of the mucosa at the scar of the previous endoscopic resection or a change in color. The results of the histopathologic examination were defined as local recurrence in cases under categories 3-5 of the Vienna classification (i.e., LGD, HGD, or adenocarcinoma).

\section{Statistical analysis}

All statistical analyses were performed using IBM SPSS Statistics version 21 (IBM Corp., Armonk, NY). Statistical significance was set at $p<0.05$. Group differences
(EMR vs. ESD) in baseline characteristics were evaluated using Pearson's chi-squared test for categorical variables. A logistic regression model was used to analyze factors affecting local recurrence. Significant univariate factors $(\mathrm{p}<0.05)$ were examined using a multivariate Cox proportional hazards regression model to identify the independent factors associated with local recurrence. Odds ratios (OR) and 95\% confidence intervals (CI) were calculated to estimate the relative risks of local recurrence. The KaplanMeier method was used to analyze the cumulative rate of local recurrence.

\section{Results}

\section{Clinicopathological characteristics}

Endoscopic resection for gastric epithelial dysplasia was performed in 905 patients. These patients were divided into an EMR group $(n=599)$ and an ESD group $(n=$ 306). Table 1 shows a comparison of the characteristics and endoscopic findings between the groups. No significant group differences in age, sex, comorbidities, social history (alcohol or smoking), and atrophic gastritis were found. Lesions $2 \mathrm{~cm}$ in size were treated significantly more frequently with EMR than with $\operatorname{ESD}(p<0.05)$. Both groups showed more lesions in the antrum than in other areas, but no statistically significant differences were noted. A depressed or reddish lesion was treated significantly more frequently with ESD than with EMR $(p<0.05)$. Moreover, the groups significantly differed in the incidences of intestinal metaplasia and H. pylori infection $(\mathrm{p}<0.05)$. In addition, when the pathology results were $\mathrm{HGD}$, the lesions were more likely to be treated with ESD than with EMR $(\mathrm{p}<0.05)$. 
Table 1 Baseline characteristics and endoscopic findings in the EMR and ESD groups

\begin{tabular}{|c|c|c|c|}
\hline & EMR $(n=599)$ & $\operatorname{ESD}(n=306)$ & $P$ value \\
\hline Age (yr), mean SD & $65.19 \pm 8.781$ & $64.50 \pm 8.099$ & 0.249 \\
\hline Sex (\%) & & & 0.694 \\
\hline Male & $432(72.1)$ & $225(73.5)$ & \\
\hline Female & $167(27.9)$ & $81(26.5)$ & \\
\hline \multicolumn{4}{|l|}{ Comorbidity (\%) } \\
\hline DM & $91(66.9)$ & $45(33.1)$ & 0.922 \\
\hline HTN & $215(63.8)$ & $122(36.2)$ & 0.246 \\
\hline COPD & $16(69.6)$ & $7(30.4)$ & 0.826 \\
\hline CKD & $12(57.1)$ & $9(42.9)$ & 0.362 \\
\hline Alcohol & $147(64.8)$ & $80(35.2)$ & 0.627 \\
\hline Smoking & $123(64.1)$ & $69(35.9)$ & 0.498 \\
\hline Location (\%) & & & 0.632 \\
\hline Upper (fundus, UB) & $117(19.5)$ & $55(18.0)$ & \\
\hline Mid (MB, LB) & $181(30.2)$ & $87(28.4)$ & \\
\hline Lower (angle, antrum) & $301(50.3)$ & $164(53.6)$ & \\
\hline Size (\%) & & & 0.006 \\
\hline $0-2 \mathrm{~cm}$ & $563(94.0)$ & 271 (88.6) & \\
\hline$>2 \mathrm{~cm}$ & $36(6.0)$ & $35(11.4)$ & \\
\hline Color change (\%) & & & 0.000 \\
\hline Redness & $188(31.4)$ & $188(61.4)$ & \\
\hline Whitish & 411 (68.6) & 118 (38.6) & \\
\hline Gross type (\%) & & & 0.000 \\
\hline Elevated & $220(36.7)$ & $50(16.3)$ & \\
\hline Flat & $175(29.2)$ & 78 (25.5) & \\
\hline Depressed & $93(15.5)$ & $129(42.2)$ & \\
\hline Nodularity & $111(18.5)$ & $49(16.0)$ & \\
\hline Atrophic change (\%) & & & 0.684 \\
\hline Closed type & $555(92.7)$ & $286(93.5)$ & \\
\hline Open type & $44(7.3)$ & $20(6.5)$ & \\
\hline \multicolumn{4}{|l|}{ Intestinal metaplasia (\%) } \\
\hline Yes & 201 (33.6) & $137(44.8)$ & 0.001 \\
\hline \multicolumn{4}{|l|}{ Helicobacter pylori (\%) } \\
\hline Positive & $70(11.7)$ & $66(21.6)$ & 0.000 \\
\hline Endoscopic biopsy (\%) & & & 0.000 \\
\hline LGD (\%) & $564(94.2)$ & $215(70.3)$ & \\
\hline HGD (\%) & $35(5.8)$ & $91(29.7)$ & \\
\hline
\end{tabular}

CKD Chronic kidney disease, COPD Chronic obstructive pulmonary disease, $D M$ Diabetes mellitus, EMR Endoscopic mucosal resection, ESD Submucosal dissection, HGD High-grade dysplasia, HTN Hypertension, $L B$ Lower body, LGD Low-grade dysplasia, MB Middle body, SD Standard deviation, UB Upper body

\section{Therapeutic outcomes}

The clinical outcomes of EMR and ESD are shown in Table 2. Complete and en bloc complete resection rates were higher in the ESD group than in the EMR group (complete resection rates, $99.0 \%$ vs. $94.8 \%$, respectively;
Table 2 Clinical outcomes of EMR and ESD

\begin{tabular}{lllr}
\hline & EMR $(n=599)$ & ESD $(n=306)$ & P value \\
\hline En bloc resection (\%) & $193(32.2)$ & $306(100)$ & 0.000 \\
Complete resection (\%) & $568(94.8)$ & $303(99.0)$ & 0.003 \\
Complication (\%) & & & 0.065 \\
$\quad$ Bleeding & $20(3.3)$ & $21(6.9)$ & \\
Perforation & 0 & 0 & \\
Stricture & $2(0.3)$ & $0(0.0)$ &
\end{tabular}

Post-procedure histopathologic result (\%)

0.000

\begin{tabular}{llll} 
Other & $31(5.2)$ & $4(1.3)$ & \\
LGD & $469(78.3)$ & $175(57.2)$ & \\
HGD & $46(7.7)$ & $76(24.8)$ & \\
Adenocarcinoma & $53(8.8)$ & $51(16.7)$ & \\
Median follow-up duration & $43.29 \pm 20.47$ & $32.21 \pm 17.60$ & \\
Local recurrence (\%) & $25(4.2)$ & $4(1.3)$ & 0.026 \\
Cumulative incidence & $25.02 \pm 18.84$ & $14.56 \pm 5.653$ & 0.286 \\
\hline EMR Endoscopic mucosal resection, ESD Submucosal dissection, HGD High-
\end{tabular}

$p=0.003$; en bloc resection rates, $100 \%$ vs. $32.2 \%$, respectively; $p<0.001$ ). No patients developed perforation after the endoscopic resection. Further, no significant differences in the incidence rate of delayed bleeding after endoscopic resection were observed between the two groups. Bleeding after ESD was frequently observed within 3 days, and bleeding after EMR was usually observed within 2 weeks. The bleeding after endoscopic resection was treated with endoscopic hemostasis through HSE injection, hemoclipping and / or APC. Pyloric stenosis occurred in only 2 of the patients who underwent EMR, without a statistically significant difference between the two groups. Pyloric stenosis after endoscopic treatment was treated with endoscopic balloon dilatation.

Figure 4 shows the histological changes before and after endoscopic resection. Of the 779 LGD patients, 109 (14\%) were histologically upgraded to HGD or adenocarcinoma after endoscopic resection. Of the $126 \mathrm{HGD}$ patients, 62 (49.2\%) were histologically upgraded to adenocarcinoma after endoscopic resection. Eight of the patients diagnosed with HGD were downgraded to LGD after endoscopic resection (about 6.3\%). In addition, no residual dysplasia was found on endoscopy after endoscopic resection in 35 patients (Table 2). In both groups, the final pathologic results after endoscopic resection showed a higher ratio of LGD compared to those of HGD and adenocarcinoma (EMR vs. ESD; 78.3\% vs. 57.2\%); however, ratios of HGD and adenocarcinoma were higher in the EMR group than in the ESD group.

Figure 5 shows the en bloc resection and complete resection rates in patients with local recurrence. Local recurrence occurred in 20 of 406 patients who underwent piecemeal resection (about 4.9\%) and in 9 of 499 


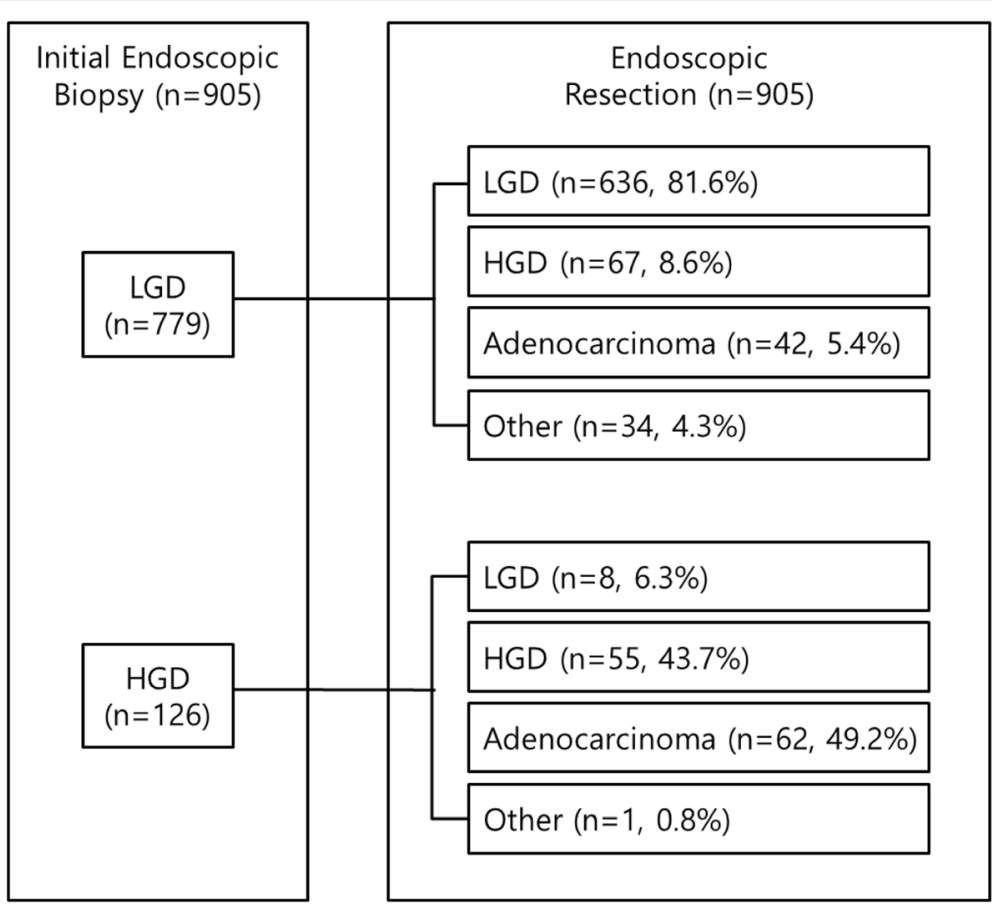

Fig. 4 Pathological changes after endoscopic resection. Other: No residual adenomatous lesion, regenerative atypia, or chronic active gastritis with intestinal metaplasia. HGD, high-grade dysplasia; LGD, low-grade dysplasia

patients who underwent en bloc resection (about 1.8\%). The local recurrence rate after endoscopic resection was significantly higher in the EMR group than in the ESD group $(p=0.026)$. One patient who experienced relapse and was finally diagnosed with adenocarcinoma underwent surgical treatment, and the rest underwent complete resection with additional endoscopic treatment for local recurrence (Fig. 5) and there was no difference between the two group (EMR vs. ESD; 100\% (25/25) vs. $75 \%$ (3/4); $p=0.153)$. There were no disease-related death among the 29 patients. The Kaplan-Meier analysis showed no significant difference in the cumulative incidence between the two groups $(p=0.286)$, with a median follow-up duration of $39.55 \pm 20.23$ months (Table 2, Fig. 6).

\section{Risk factors for local recurrence by logistic regression analysis}

Table 3 shows the results of the univariate logistic regression analysis of the risk factors for local recurrence. The local recurrence rate after endoscopic resection was higher for lesions $>2 \mathrm{~cm}$ than for those $2 \mathrm{~cm}$ (OR 4.037, $p=0.002)$. In addition, the local recurrence rate was significantly lower when en bloc resection and complete resection were performed (en bloc resection, OR 0.011, $p=0.011$; complete resection, OR $0.164, p=0.001$ ). In terms of the endoscopic resection method, the local recurrence rate was lower with ESD than with EMR (OR $0.304, p=0.028$ ). Table 4 shows the results of the multivariate logistic regression analysis of the risk factors for local recurrence. The local recurrence rate was higher in cases with larger lesions, and was lower when complete resection or ESD was performed.

\section{Discussion}

Previous studies comparing clinical outcomes according to endoscopic resection methods have focused mostly on early gastric cancer, and there have been few studies on gastric dysplasia alone. Therefore, this study was carried out to compare the local recurrence rates for EMR and ESD and to identify the risk factors of local recurrence. The results showed that the complete resection rate was significantly higher, and the local recurrence rate was significantly lower, in patients with gastric epithelial dysplasia treated with ESD rather than with EMR.

According to the National Cancer Information Center of Korea, as of 2016, stomach cancer had the highest incidence, at 35\%, compared to that for other solid cancers [7]. In Korea, gastroduodenoscopy during a health checkup is recommended every 2 years, starting at the age of 40 years. Therefore, the diagnosis of gastric dysplasia, as well as early gastric cancer, is increasing. According to the Correa hypothesis, gastric dysplasia is a precancerous lesion that progresses from gastric atrophy and intestinal metaplasia to adenocarcinoma through hypoplasia or dysplasia [8]. However, a previous study on the natural course of gastric dysplasia showed that LGD 


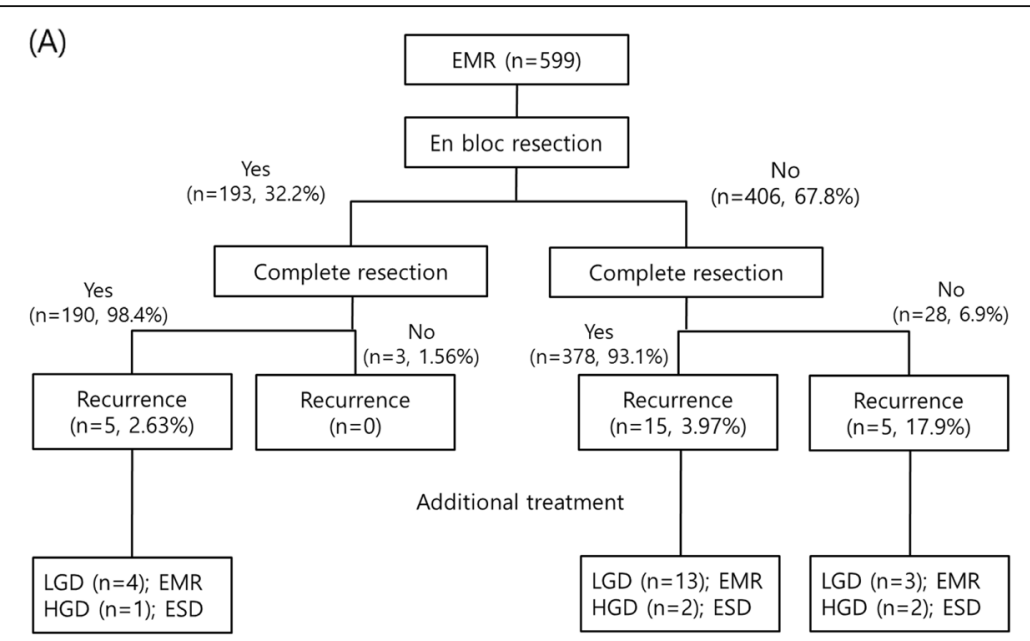

(B)

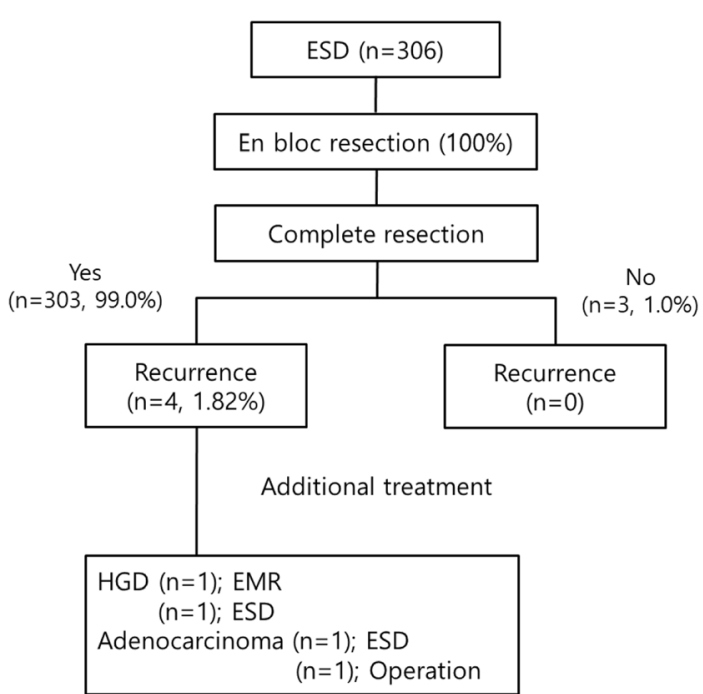

Fig. 5 Clinical course after endoscopic resection. a In the EMR group, the piecemeal resection rate was relatively high, and local recurrence occurred in $17.9 \%$ of patients who did not undergo both en bloc and complete resection. $\mathbf{b}$ In the ESD group, local recurrence occurred in about $1.82 \%$ of patients with both en bloc and complete resection, which is lower than the rate in the EMR group. EMR, endoscopic mucosal resection; ESD, endoscopic submucosal dissection; HGD, high-grade dysplasia; LGD, low-grade dysplasia

progressed to adenocarcinoma at a relatively low rate of about $0-23 \%$, while HGD showed a higher progression rate of about $10-81 \%$ [9]. In a recent study that followed patients with gastric dysplasia for 7 years, only $7.8 \%$ of patients with LGD cases progressed to cancer during followup, while $63.6 \%$ of those with HGD cases progressed to cancer [10]. In the present study, the final pathological diagnosis was not changed after endoscopic resection in $81.6 \%$ of LGD patients, but $49.2 \%$ of HGD patients were diagnosed with adenocarcinoma after endoscopic resection (Fig. 2). Thus, there is no question that HGD requires endoscopic resection or surgical treatment because of its potential for cancer progression and the coexistence of cancer cells. In contrast, LGD has a relatively low risk of malignant transformation, and spontaneously regresses in
$32-59 \%$ of patients in previous studies [11-16]. The American Society for Gastrointestinal Endoscopy and the British Society of Gastroenterology guidelines recommend endoscopic resection for gastric dysplasia of any size, if possible $[17,18]$. The European guidelines also recommend grading and resecting dysplasia in patients with visible endoscopic lesions. If there is no visible endoscopic lesion, it is necessary to confirm the lesion by magnification chromoendoscopy and/or narrow-band imaging. If the lesion is confirmed, a biopsy is performed, and if the diagnosis is LGD, follow-up endoscopy should be performed within 12 months [19]. In Korea, because LGD may sometimes progress to cancer, endoscopic resection is performed, unless it is impossible because of advanced age or comorbid disease. 


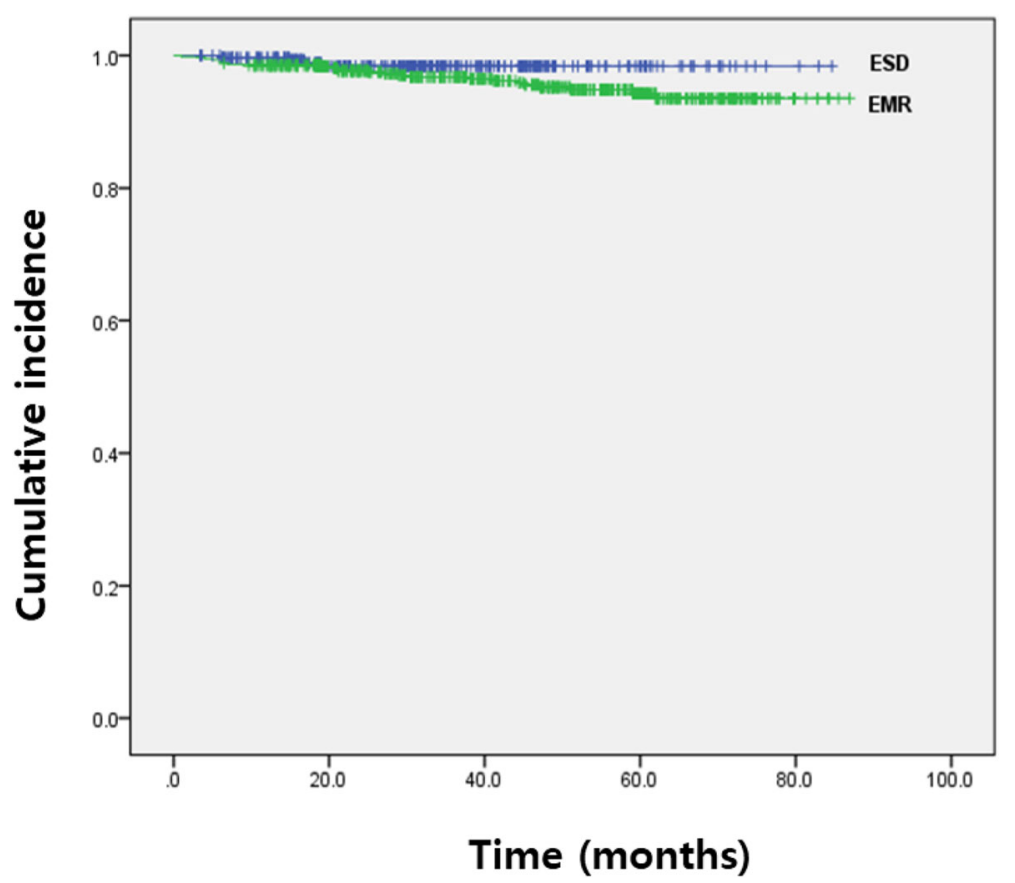

Fig. 6 Cumulative incidence of local recurrence after EMR or ESD. Kaplan-Meier curves show the trend of the development of local recurrence after endoscopic resection. EMR, endoscopic mucosal resection; ESD, endoscopic submucosal dissection

Gastric dysplasia is mainly treated by endoscopic resection, but argon plasma coagulation (APC) is also used. Several studies have shown that the removal of gastric dysplasia through APC curettage is a good option because of the short hospitalization period, low medical costs, and low complication rates [20, 21]. However, APC is effective for only relatively small-sized LGD lesions $(2.0 \mathrm{~cm})$, and the local recurrence rate is higher than that with other endoscopic methods [21]. In addition, since the tissue cannot be collected, determining the final histological diagnosis of the lesion is difficult. Therefore, ESD and EMR are considered as standard treatments for gastric dysplasia, and are used as an additional method to remove remaining lesions after endoscopic resection.

In comparison with conventional EMR, ESD requires a long treatment time and advanced operator skills, and has disadvantages associated with complications such as perforation. However, the advantages of ESD are the en bloc resection of large lesions, high complete resection rate, and low local recurrence rate $[9,22-26]$.

In a 2010 study on the predictive factors for local recurrence after endoscopic resection for early gastric cancer, a larger lesion size and treatment with EMR were associated with increased an incomplete resection rate, and had a significant impact on local recurrence [27]. Data from this study showed that en bloc resection can be an important predictor of local recurrence. Histologic type, comorbidities, location of the lesion, color of the lesion, gross type, and presence of $H$. pylori infection were not correlated with local recurrence; only the size of the lesion and an incomplete resection were risk factors of local recurrence. In this study related to recurrence after resection of gastric dysplasia, most cases of relapse after endoscopic treatment could be treated with additional endoscopic resection $(97 \%, 28 / 29)$ Also, this shows that even for the lesions resected with EMR, the most of them could achieve complete eradication on a subsequent endoscopy by repeating the EMR.

The present study has several limitations. First, the study was retrospective in nature and was conducted at a single center. Endoscopic resection was performed by four endoscopists, and EMR or ESD procedures were chosen according to their subjective judgment, in the absence of definitive treatment guidelines for gastric dysplasia. The individual endoscopists may also have influenced clinical outcomes; although they were trained at the same institution, they differed in experience and preferences, such as the use of particular knives and electrocoagulation modes. Thus, the en bloc resection rate may vary depending on the endoscopist. Therefore, multicenter and prospective studies are needed to confirm our results. Second, the duration of follow-up was not constant. We analyzed data from patients who underwent endoscopic resection between January 2011 and December 2015 and were followed for at least 1 year after the procedure. Therefore, our observation periods ranged between 7 (long-term) and 3 years (short-term). 
Table 3 Univariate logistic regression analysis of the risk factors for local recurrence

\begin{tabular}{|c|c|c|}
\hline & Univariat & \\
\hline & $P$ value & OR $(95 \% \mathrm{Cl})$ \\
\hline Size & & \\
\hline $0-2 \mathrm{~cm}$ vs. $>2 \mathrm{~cm}$ & 0.002 & 4.037 (1.661-9.809) \\
\hline Color change & & \\
\hline Redness & 0.716 & $1.148(0.546-2.416)$ \\
\hline Gross type & & \\
\hline Elevated & 0.292 & \\
\hline Elevated vs. flat & 0.871 & $0.913(0.303-2.753)$ \\
\hline Elevated vs. depressed & 0.710 & $1.223(0.423-3.541)$ \\
\hline Elevated vs. nodularity & 0.117 & $2.239(0.817-6.135)$ \\
\hline Atrophic change & & \\
\hline Closed type & 0.450 & $2.170(0.290-16.211)$ \\
\hline Intestinal metaplasia & & \\
\hline Yes & 0.220 & $1.590(0.758-3.337)$ \\
\hline Helicobacter pylori & & \\
\hline Yes & 0.111 & $0.196(0.026-1.453)$ \\
\hline Endoscopic biopsy & & \\
\hline LGD vs. HGD & 0.113 & $2.024(0.846-4.842)$ \\
\hline En bloc resection & & \\
\hline Yes & 0.011 & $0.354(0.160-0.787)$ \\
\hline Complete resection & & \\
\hline Yes & 0.001 & $0.164(0.059-0.461)$ \\
\hline Complication & & \\
\hline Yes & 0.998 & 0.000 \\
\hline Pathologic result of post-proce & & \\
\hline Other $^{a}$ & 0.424 & \\
\hline Other vs. LGD & 0.983 & $0.978(0.127-7.541)$ \\
\hline Other vs. HGD & 0.503 & $2.070(0.246-17.414)$ \\
\hline Other vs. adenocarcinoma & 0.993 & $1.010(0.102-10.036)$ \\
\hline Procedure & & \\
\hline ESD & 0.028 & $0.304(0.105-0.882)$ \\
\hline
\end{tabular}

Third, in the present study, although we investigated $H$. pylori infection and eradication treatments, the effects of the presence or absence of $H$. pylori and eradication were not clear. Thus, further studies are needed to determine their association with local recurrence. Fourth, accurate tumor size measurement is critical for selecting proper candidates for endoscopic resections (ER) of gastric neoplasia. However, size discrepancy between endoscopic size and pathologic size often occurs during ER for gastric tumor.
Table 4 Multivariate logistic regression analysis of the risk factors for local recurrence

\begin{tabular}{lll}
\hline & \multicolumn{2}{c}{ Multivariate } \\
\cline { 2 - 3 } & P value & OR $(95 \% \mathrm{Cl})$ \\
\hline Size & 0.006 & $3.893(1.489-10.180)$ \\
$\quad 0-2 \mathrm{~cm}$ vs. $>2 \mathrm{~cm}$ & & \\
$\begin{array}{l}\text { Complete resection } \\
\text { Yes }\end{array}$ & 0.030 & $0.292(0.096-0.887)$ \\
$\begin{array}{l}\text { Procedure } \\
\text { ESD }\end{array}$ & 0.027 & $0.293(0.098-0.872)$ \\
\hline Cl Confidence intervals, ESD Submucosal dissection, OR Odds ratio
\end{tabular}

One strength of the present study is its focus on the endoscopic resection of gastric dysplasia, which is a precancerous lesion, and its determination of the local recurrence rate according to the endoscopic resection method. Furthermore, the discrepancy in the pathological diagnosis before and after endoscopic resection of gastric dysplasia was investigated.

\section{Conclusions}

The present study showed that approximately $49.2 \%$ of HGD cases were upgraded histologically to adenocarcinoma after endoscopic resection. In addition, local recurrence rates were higher in patients with lesions $>2 \mathrm{~cm}$, histologically incomplete resection. Therefore, in cases of gastric dysplasia with HGD or a lesion $>2 \mathrm{~cm}$, ESD is preferred to EMR due to its higher incomplete resection rate, which can help prevent local recurrence and also EMR may be possible for low-grade dysplasia that is less than $2 \mathrm{~cm}$ without surface changes such as redness, depression and nodularity.

\section{Abbreviations}

APC: Argon plasma coagulation; EMR: Endoscopic mucosal resection; ESD: Endoscopic submucosal dissection; HGD: High-grade dysplasia;

LGD: Low-grade dysplasia

\section{Acknowledgements}

Not applicable.

\section{Authors' contributions}

HSM supervised the entire study and participated in the study design. MKB, JHP, JSK, SHK, JKS, ESL, SHK, BSL, and HYJ analyzed and interpreted the data. MKB and ISK performed statistical analyses. MKB and HSM wrote the manuscript. The authors read and approved the final manuscript.

\section{Funding}

This study received no financial support.

\section{Availability of data and materials}

The datasets used and analyzed in the current study are available from the corresponding author on reasonable request.

\section{Ethics approval and consent to participate}

This study conducted in accordance with the ethical standards of the declaration of Helsinki. The requirement for informed consent from the patients was waived because of the retrospective nature of this study, and this study protocol was approved by the institutional review board of Chungnam National University Hospital (CNUH 2019-03-073). 


\section{Consent for publication}

Not applicable.

\section{Competing interests}

The authors declare that they have no competing interests.

\section{Author details}

'Division of Gastroenterology, Department of Internal Medicine, Chungnam National University Hospital, Chungnam National University School of Medicine, 282 Munhwa-ro, Jung-gu, Daejeon 35015, Korea. ${ }^{2}$ Division of Gastroenterology, Department of Internal Medicine, Chungnam National University Hospital, Chungnam National University School of Medicine, 282 Munhwa-ro, Jung-gu, Daejeon 35015, Republic of Korea. ${ }^{3}$ Clinical Trials Center, Chungnam National University Hospital, Daejeon 34952, Korea.

Received: 17 July 2019 Accepted: 5 May 2020

Published online: 12 May 2020

\section{References}

1. Yoon WJ, Lee DH, Lee KL, Kyeong JD, Kwan KB, Won KJ, et al. The discordance between endoscopic forceps biopsy and endoscopic resection specimen of gastric polyps. Korean J Med. 2005;69:481-6.

2. Kim SY, Sung JK, Moon HS, Kim KS, Jung IS, Yoon BY, et al. Is endoscopic mucosal resection a sufficient treatment for low-grade gastric epithelial dysplasia? Gut Liver. 2012:6:446-51.

3. Chung IK, Lee JH, Lee SH, Kim SJ, Cho JY, Cho WY, et al. Therapeutic outcomes in 1000 cases of endoscopic submucosal dissection for early gastric neoplasms: Korean ESD study group multicenter study. GastrointestEndosc. 2009:69:1228-35.

4. Jang JS, Choi SR, Graham DY, Kwon HC, Kim MC, Jeong JS, et al. Risk factors for immediate and delayed bleeding associated with endoscopic submucosal dissection of gastric neoplastic lesions. Scand J Gastroenterol. 2009:44:1370-6.

5. lizuka H, Kakizaki S, Sohara N, Onozato Y, Ishihara H, Okamura S, et al. Stricture after endoscopic submucosal dissection for early gastric cancers and adenomas. Dig Endosc. 2010;22:282-8.

6. Schlemper RJ, Riddell RH, Kato Y, Borchard F, Cooper HS, Dawsey SM, et al. The Vienna classification of gastrointestinal epithelial neoplasia. Gut. 2000; 47:251-5.

7. National Cancer Information Center 2016. Available from: https://www. cancer.go.kr/lay1/S1T639C641/contents.do. Accessed 16 Jan 2019.

8. Correa P. A human model of gastric carcinogenesis. Cancer Res. 1988;48: 3554-60.

9. Choi SI, Park JC. The natural history and treatment strategy of gastric adenoma as a pre-cancerous lesion. Korean J Helicobacter Up Gastrointest Res. 2018;18:103-9.

10. Li D, Bautista MC, Jiang SF, Daryani P, Brackett M, Armstrong M, et al. Risks and predictors of gastric adenocarcinoma patients with gastric intestinal metaplasia and dysplasia: a population-based study. Am J Gastroenterol. 2016;111:1104-13.

11. Sung JK. Diagnosis and management of gastric dysplasia. Korean J Intern Med. 2016;31:201-9.

12. Rugge M, Nitti D, Farinati F, di Mario F, Genta RM. Non-invasive neoplasia of the stomach. Eur J GastroenterolHepatol. 2005;17:1191-6.

13. Weinstein WM, Goldstein NS. Gastric dysplasia and its management. Gastroenterology. 1994;107:1543-5.

14. Rugge M, Farinati F, Baffa R, Sonego F, Di Mario F, Leandro G, et al. Gastric epithelial dysplasia in the natural history of gastric cancer: a multicenter prospective follow-up study. Gastroenterology. 1994;107:1288-1296.

15. Bearzi I, Brancorsini D, Santinelli A, Rezai B, Mannello B, Ranaldi R. Gastric dysplasia: a ten-year follow-up study. Pathol Res Pract. 1994;190:61-8.

16. Rugge M, Cassaro M, Di Mario F, Sonego F, Di Mario F, Leandro G, et al. The long term outcome of gastric non-invasive neoplasia. Gut. 2003:52:1111-6.

17. ASGE Standards of Practice Committee, Evans JA, Chandrasekhara V, Chathadi KV, Decker GA, Early DS, et al. The role of endoscopy in the management of premalignant and malignant conditions of the stomach. GastrointestEndosc. 2015;82:1-8.

18. Goddard AF, Badreldin R, Pritchard DM, Walker MM, Warren B. British Society of Gastroenterology. The management of gastric polyps. Gut. 2010;59:1270-6.
19. Dinis-Ribeiro M, Areia M, de Vries AC, Marcos-Pinto R, Monteiro-Soares M, O'Connor A, et al. Management of precancerous conditions and lesions in the stomach (MAPS): guideline from the European Society of Gastrointestinal Endoscopy (ESGE), European helicobacter study group (EHSG), European Society of Pathology (ESP), and the Sociedade Portuguesa de EndoscopiaDigestiva (SPED). Endoscopy. 2012;44:74-94.

20. Lee DH, Bae WK, Kim JW, Paik WH, Kim NH, Kim KA, et al. The usefulness of argon plasma coagulation compared with endoscopic submucosal dissection to treat gastric adenoma. Korean J Gastroenterol. 2017;69:283-90.

21. Jung SJ, Cho SJ, Choi IJ, , Kook MC, Kim CG, Lee JY, et al. Argon plasma coagulation is safe and effective for treating smaller gastric lesions with low-grade dysplasia: a comparison with endoscopic submucosal dissection. SurgEndosc. 2013;27:1211-1218.

22. Watanabe K, Ogata S, Kawazoe S, Watanabe K, Koyama T, Kajiwara T, et al. Clinical outcomes of EMR for gastric tumors: historical pilot evaluation between endoscopic submucosal dissection and conventional mucosal resection. GastrointestEndosc. 2006;63:776-82.

23. ASGE Technology Committee, Kantsevoy SV, Adler DG, Conway JD, Diehl DL, Farraye FA, et al. Endoscopic mucosal resection and endoscopic submucosal dissection. Gastrointest Endosc. 2008;68:11-8.

24. Kim JW, Jang JY. Optimal management of biopsy-proven low-grade gastric dysplasia. World J GastrointestEndosc. 2015;7:396-402.

25. Jang GH, Kim HH, Ahn SY. Feasibility of planned endoscopic submucosal dissection with snaring for gastric adenoma compared with standard endoscopic submucosal dissection. Korean J Helicobacter Up Gastrointest Res. 2014;14:174-80.

26. Lian J, Chen S, Zhang Y, Qiu F. A meta-analysis of endoscopic submucosal dissection and EMR for early gastric cancer. GastrointestEndosc. 2012;76: 763-70

27. Park JC, Lee SK, Seo JH, et al. Predictive factors for local recurrence after endoscopic resection for early gastric cancer: long-term clinical outcome in a single-center experience. SurgEndosc. 2010;24:2842-9.

\section{Publisher's Note}

Springer Nature remains neutral with regard to jurisdictional claims in published maps and institutional affiliations.

Ready to submit your research? Choose BMC and benefit from:

- fast, convenient online submission

- thorough peer review by experienced researchers in your field

- rapid publication on acceptance

- support for research data, including large and complex data types

- gold Open Access which fosters wider collaboration and increased citations

- maximum visibility for your research: over $100 \mathrm{M}$ website views per year

At $\mathrm{BMC}$, research is always in progress.

Learn more biomedcentral.com/submissions 